\title{
Eps15 homology domain 1 promotes the evolution of papillary thyroid cancer by regulating endocytotic recycling of epidermal growth factor receptor
}

\author{
YU LIU ${ }^{1}$, YANAN LIANG ${ }^{1,2}$, MING LI $^{3}$, DUANYANG LIU ${ }^{1}$, JING TANG $^{1}$, \\ WEIWEI YANG $^{1}$, DANDAN TONG ${ }^{1}$ and XIAOMING JIN ${ }^{1}$ \\ ${ }^{1}$ Department of Pathology; ${ }^{2}$ College of Pharmacy, Harbin Medical University; ${ }^{3}$ Institute of Iodine Deficiency Disorders, \\ Center for Endemic Disease Control, Chinese Center for Disease Control and Prevention, \\ Harbin Medical University, Harbin, Heilongjiang 150081, P.R. China
}

Received October 22, 2017; Accepted June 15, 2018

DOI: $10.3892 / \mathrm{ol} .2018 .9200$

\begin{abstract}
Papillary thyroid cancer (PTC) is the most common type of thyroid malignancy, and it is often observed to overexpress epidermal growth factor receptor (EGFR). Previous research has indicated that $\mathrm{EH}$ domain-containing 1 (EHD1) is associated with EGFR-mediated endocytotic recycling in multiple tumor types. The objective of the present study was to determine the protein expression levels and clinical significance of EHD1, EGFR, caveolin-1 (CAV-1) and RAB11 family interacting protein 3 (RAB11FIP3) in PTC. PTC specimens were analyzed for EHD1, EGFR, CAV-1 and RAB11FIP3 expression via immunohistochemistry and western blotting. The associations between protein expression and clinicopathological features were assessed. EHD1, EGFR, CAV-1 and RAB11FIP3 expression levels were increased in human PTC. Additionally, the expression level of EHD1 protein was significantly associated with tumor size, lymph node metastasis and EGFR expression $(\mathrm{P}<0.05)$. CAV-1 was associated with tumor size and EGFR expression $(\mathrm{P}<0.05)$. EGFR was only associated with lymph node metastasis $(\mathrm{P}=0.027)$ and RAB11FIP3 was not associated with any clinicopathological characteristics. The correlations between EHD1 and EGFR $(r=0.564, \mathrm{P}<0.05), \mathrm{CAV}-1 \quad(\mathrm{r}=0.865$, $\mathrm{P}<0.01)$ and RAB11FIP3 ( $\mathrm{r}=0.504, \mathrm{P}<0.05)$ were statistically significant. Overall, EHD1, CAV-1 and RAB11FIP3, which are key proteins in endocytotic recycling, promote PTC tumorigenesis through the regulation of the transport of EGFR.
\end{abstract}

Correspondence to: Dr Dandan Tong or Professor Xiaoming Jin, Department of Pathology, Harbin Medical University, 157 Baojian Road, Nangang, Harbin, Heilongjiang 150081, P.R. China

E-mail: tongdd1977@163.com

E-mail: jinxm55@163.com

Key words: papillary thyroid cancer, EH domain-containing 1, epidermal growth factor receptor, caveolin-1, RAB11 family interacting protein 3

\section{Introduction}

In the last decade, the incidence of thyroid carcinoma has rapidly increased, and its worldwide incidence has more than doubled, accounting for between 2.7 and 17\% of all thyroid tumors (1). Papillary thyroid cancer (PTC) is the most common type of thyroid malignancy. The rate of PTC is the fastest growing amongst thyroid malignancies in women, and the ratio of incidence between men and women is 1:2.58 (2). The incidence of PTC has also rapidly increased in China in recent years (2).

Epidermal growth factor receptor (EGFR), which is located mainly in the cell membrane, is a member of the receptor tyrosine kinases (3). Overexpression of EGFR and/or its ligands is frequently observed in human cancer. In addition, it has been demonstrated that activating mutations of EGFR are direct determinants of oncogenic transformation in breast, ovarian and non-small cell lung cancer (4-6). It has been demonstrated that expression of EGFR is an independent prognostic factor in thyroid cancer (7). Previous research has indicated that endocytotic recycling of EGFR may be the underlying molecular mechanism for its increase (8). Caveolin-1 (CAV-1), Eps15 homology domain 1 (EHD1) and RAB11 family interacting protein 3 (RAB11FIP3) serve an important function in endocytotic recycling.

CAV-1, an essential protein constituent of the caveolae gene family, participates in vesicular trafficking and signal transduction, and serves an important function in cell proliferation, differentiation, migration, apoptosis and angiogenesis $(9,10)$. EGFR interacts with $\mathrm{CAV}-1$ through a CAV-binding sequence motif located in its intracellular kinase domain (7). Mutations in CAV-1 or abnormal CAV-1 expression may increase the expression of EGFR $(11,12)$.

The C-terminal EGFR pathway substrate 15 homology domain/receptor-mediated endocytosis-1 family is a novel group of endosomal scaffolding molecules that are required for receptor recycling. It is notable that the most typical role for EHD1 is the recycling of transmembrane cargo from the endosomal-recycling compartment (ERC) to the plasma membrane, which is mediated by clathrin-dependent and -independent mechanisms $(13,14)$. 
RAB proteins (Ras-related protein) serve a major function in vesicle budding, delivery, tethering and fusion; for example, the RAB11 GTPase subfamily members are enriched on the ERC and regulate membrane trafficking through the ERC $(15,16)$. RAB11FIPs or FIP3, which are common in the RAB11-positive ERC, are the most prominent members of this subfamily $(17,18)$. FIP3, which is located on the ERC during interphase, is required to maintain the structural integrity of the ERC; furthermore, it also participates in the process of membrane transport from the ERC to the site of membrane insertion during cell division (17-19).

Endocytotic recycling is an important means for the transport of biological macromolecules and proteins, and serves an important role in normal cell metabolism and material transport in the human body. In normal cells, EGFR internalizes to activate signaling and then enters the lysosome for degradation, or accesses the ERC and returns to the cell membrane via EHD1- and RAB11FIP3-mediated 'slow recycling' (20). We hypothesize that in tumor cells, EHD1 expression increases and accelerates the recycling of EGFR, and it may extend the signal duration and effect, which is conducive for tumor development.

In the present study, the expression of EHD1, EGFR, CAV-1 and RAB protein was measured in patients with PTC, and the correlation between EHD1, EGFR, CAV-1 and RAB protein expression was analyzed. The aim of the present study was to investigate whether the proteins involved in endocytotic recycling are also involved in EGFR overexpression and tumor evolution in PTC, and to assess the underlying molecular mechanism of this function.

\section{Materials and methods}

Tissue samples. A total of 72 pairs of paraformaldehyde-fixed paraffin-embedded specimens were collected from patients with PTC (median age, 45 years; age range, 27-64 years; male: female ratio, 1:8) resection between January 2012 and December 2014. Tumor specimens were divided into two parts. One was fixed in $4 \%$ formaldehyde for $24 \mathrm{~h}$ at $4^{\circ} \mathrm{C}$, and then routinely processed into paraffin blocks; the other were snap frozen in liquid nitrogen, and stored at $-80^{\circ} \mathrm{C}$ until subsequent use further detection. None of the patients in this study had received radiation or chemotherapy prior to surgery. The clinicopathological characteristics of the patients examined are summarized in Table I. The clinicopathological features did not include tumor grade and tumor stage, thus these features were not investigated. The study was retrospective, and the cases, which represent a spectrum of PTCs, were retrieved from the Third Affiliated Hospital of Harbin Medical University (Heilongjiang, China).

Immunohistochemistry (IHC). The aforementioned 72 PTC tissue sections were deparaffinized with xylene and rehydrated in a descending alcohol series $(85,95,100 \%)$. Subsequently, the sections were soaked in citrate ( $\mathrm{pH} \mathrm{6.0)}$ and autoclaved at $120^{\circ} \mathrm{C}$ for $2 \mathrm{~min}$ for antigen retrieval, then cooled for $30 \mathrm{~min}$ to room temperature. $\mathrm{H}_{2} \mathrm{O}_{2}$ (3\%) was used to quench the samples, and 5\% goat serum (OriGene Technologies, Inc., Beijing, China) was used to block the samples for $10 \mathrm{~min}$ at room temperature. Rabbit monoclonal antibody against
Table I. Clinical and pathological characteristics of 72 patients.

Characteristic

Tissues, $\mathrm{n}$

Sex

Male

8

Female

64

Male:female ratio

$1: 8$

Age, years

$<45$

46

$\geq 45$

26

Tumor size, $\mathrm{cm}$

$<2$

52

$\geq 2$

20

Lymph node metastasis

No

Yes

23

EHD1 (cat. no. ab109311; Abcam, Cambridge, UK), rabbit monoclonal antibody against EGFR (cat. no. 4267; Cell Signaling Technology, Inc., Danvers, MA, USA), mouse polyclonal antibody against CAV-1 (cat. no. 3238; Cell Signaling Technology, Inc.) and rabbit polyclonal antibody against RAB11FIP3 (cat. no. LS-C120286; LifeSpan BioSciences, Inc., Seattle, WA, USA) were used as primary antibodies. The sections were incubated overnight at $4^{\circ} \mathrm{C}$ with these primary antibodies, which were diluted at 1:100, 1:45, 1:80 and 1:80, respectively, followed by incubation with biotinylated sheep anti-rabbot IgG or goat anti-mouse IgG secondary antibodies (SPN-9001 or SPN-9002; Origenes Technclogies, Inc.) at room temperature for $30 \mathrm{~min}$. The sections were then stained with DAB. Following hematoxylin staining (5 $\mathrm{min}$ in room temperature) according to the standard procedure and gradient dehydration, the sections were mounted. Double-blind analysis was performed on all samples by two independent investigators (Department of Pathology in Harbin Medical University, Harbin, China) without any prior knowledge of the clinicopathological data.

The results of IHC were scored using the following standard: Staining intensity was divided into four grades according to the percentage of stained cells relative to the total number of cells. The samples were given a grade as follows based on the number of the cells stained: -, 0-5\%; +, 6-25\%; ,$++ 26-50 \%$; and +++, 51-100\%. Samples were sorted into two categories based on their positive staining rate and a threshold of 5\% was used for EHD1, EGFR, CAV-1 and RAB11FIP3. 'Positive' indicates that the percentage of stained cells was $>5 \%$, while 'negative' indicates that the percentage of stained cells was $\leq 5 \%$.

Western blot analysis. A total of 30 pairs of fresh PTC tissues obtained from the afformentioned 72 tissues were lysed with radioimmunoprecipitation assay lysis buffer (P0013B; Beyotime Institute of Biotechnology, Haimen, China) in the presence of protease inhibitors (04693159001; Roche Diagnostics, Basel, Switzerland). Samples were heated for $5 \mathrm{~min}$ at $95^{\circ} \mathrm{C}$. Protein concentration were determined by a 
A

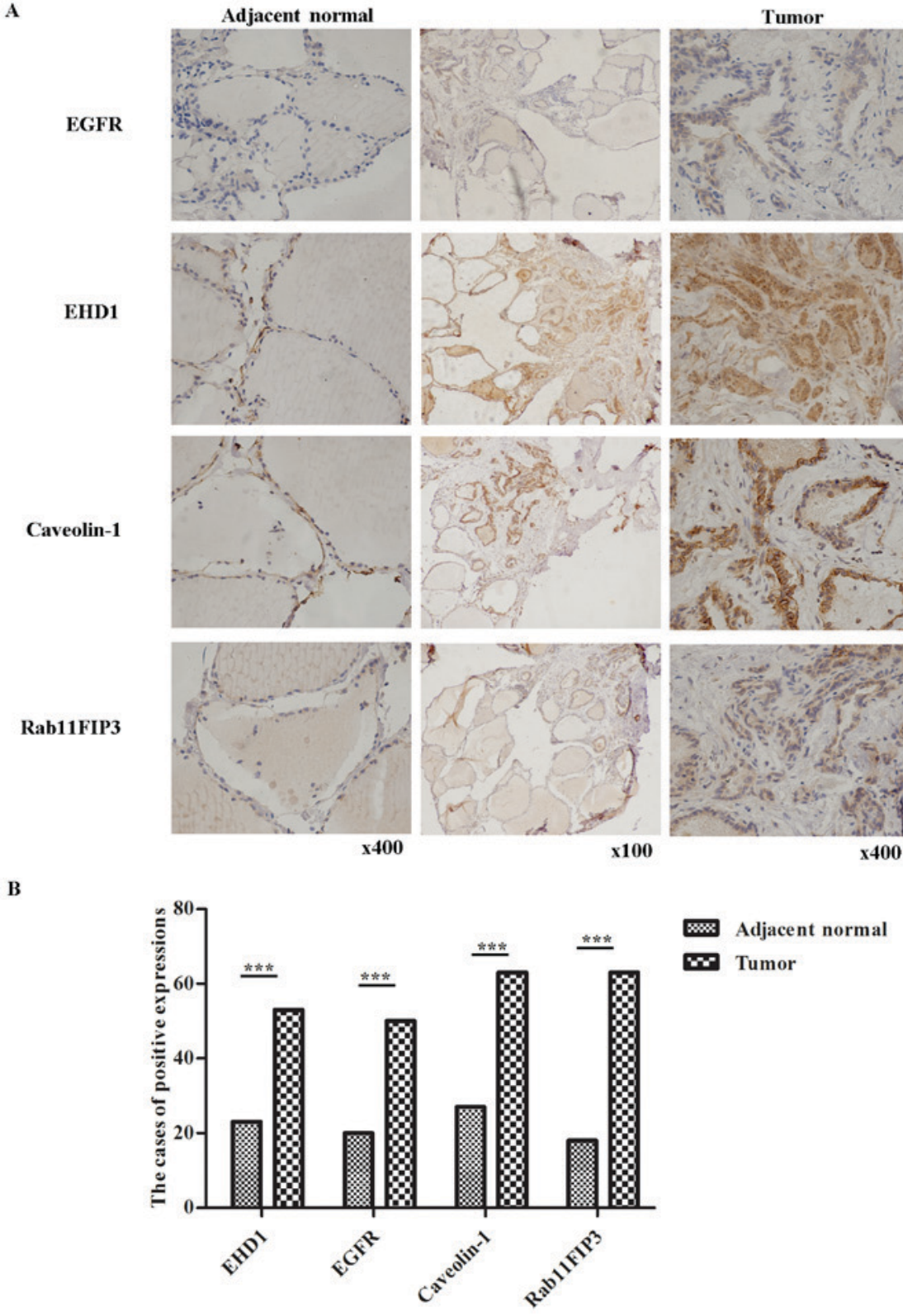

Figure 1. Immunohistochemical analysis of protein expression in adjacent normal tissues and tumor tissues of papillary thyroid cancer $(\mathrm{n}=72)$. (A) Representative samples expressing high EHD1, EGFR, RAB11FIP3 and CAV-1 in tumor tissues relative to normal tissues. Representative samples of EHD1, EGFR, RAB11FIP3 and CAV-1 expression (brown color staining), as detected by immunohistochemistry in a pair of tumor tissues and adjacent normal tissues. (B) Compared with adjacent normal tissues, tumor tissues expressed significantly increased EHD1 ( $\mathrm{P}<0.01)$, EGFR ( $\mathrm{P}<0.01), \mathrm{CAV}-1$ ( $\mathrm{P}<0.01)$ and RAB11FIP3 $(\mathrm{P}<0.01)$ expression. Fig. 1B was created from the data of Table II. ${ }^{* * *} \mathrm{P}<0.001$. EHD1, EH domain-containing 1; EGFR, epidermal growth factor receptor; RAB11FIP3, RAB11 family interacting protein 3; CAV-1, caveolin-1.

BCA assay and equal amounts of protein lysate $(100 \mu \mathrm{g})$ were resolved using SDS-PAGE (12\% gel). Polyvinylidene difluoride (PVDF) membranes (EMD Millipore, Billerica, MA, USA) were cut according to the size of the gel and used for electrotransfer. For immunoblotting, antibodies against EGFR (Cell Signaling Technology,Inc.), EHD1 (Abcam), CAV-1 (Cell Signaling Technology, Inc.) and GAPDH (Sigma-Aldrich; Merck KGaA, Darmstadt, Germany) were used. GAPDH solution was diluted with TBS with Tween-20 (TBST) at 1:5,000 and incubated with the PVDF membrane overnight at $4^{\circ} \mathrm{C}$. The other primary antibody solutions were diluted at 1:1,000 and incubated with the PVDF membrane overnight at $4^{\circ} \mathrm{C}$. Subsequently, the membranes were washed 3 times with TBST and then a 1:5,000 dilution of the horseradish peroxidase-conjugated goat anti-mouse $\operatorname{IgG}$ or goat anti-rabbit IgG secondary antibodies (ZB-2305 or ZB-2308 respectively; Origene Technologies, Inc.), which was diluted with TBST, was incubated with the membrane with agitation for $1 \mathrm{~h}$ at room temperature. Quantity One 4.62 software (Bio-Rad Laboratories Inc., Hercules, CA, USA) was used for denistometric analysis.

Statistical analysis. The SPSS statistical software package (version 17.0; SPSS, Inc., Chicago, IL, USA) was used for statistical calculations. The comparison between two or multiple rates was performed using the $\chi^{2}$ test or Continuity Correction test. Spearman's correlation coefficient test was used to evaluate correlations between EHD1 and the other proteins. 
The data are expressed as the mean \pm standard deviation where applicable. One-way analysis of variance was used to analyze the differences between groups with Fisher's least significant difference post-hoc test. An independent t-test was used for comparison of differences in the mean value. $\mathrm{P}<0.05$ was considered to indicate a statistically significant difference.

\section{Results}

Expression level of EHD1, EGFR, RAB11FIP3 and CAV-1 in human PTC tissues. Characteristics describing the 72 patients included in the study are summarized in Table I. To determine whether EHD1 serves a function in endocytotic recycling of EGFR, the expression of EHD1, EGFR, RAB11FIP3 and $\mathrm{CAV}-1$ was investigated. A representative sample of immunostaining with antibodies against EHD1, EGFR, RAB11FIP3 and CAV-1 is presented in Fig. 1A. Using IHC, EHD1 expression was detected in the cell nucleus and EGFR, RAB11FIP3 and CAV-1 expression in the cytoplasm of the cancer tissues. IHC revealed that the nuclear expression of EHD1 was increased in PTC tissues, with $73.6 \%$ of tumors being positive for EDH1 expression, while only $31.9 \%$ were positive in tumor-adjacent normal tissues. The frequency of positive staining was $69.4 \%$ for EGFR, $87.5 \%$ for CAV-1 and 87.5\% for RAB11FIP3 in the PTC samples $(\mathrm{n}=72)$. The frequency of positive staining was $27.8 \%$ for EGFR, $37.5 \%$ for CAV-1 and 25\% for RAB11FIP3 in normal tissues $(n=72)$. As presented in Fig. 1B and Table II, it was identified that compared with adjacent normal tissues, cancer tissues expressed significantly higher levels of EHD1 in the nucleus and significantly higher levels of EGFR, CAV-1 and RAB11FIP3 in the cytoplasm (all $\mathrm{P}<0.01$ ).

The protein expression level of EHD1, EGFR and CAV-1 was also evaluated in 30 pairs of PTC and non-tumor samples by western blotting. The RAB11FIP3 expression data were not associated with the clinicopathological features of the patient samples by IHC and therefore were not analyzed by western blotting.

PTC exhibited higher levels of EGFR, EHD1 and CAV-1 compared with adjacent normal tissues (Fig. 2A). Furthermore, statistical analysis revealed a significant difference in the mean expression levels of EGFR, EHD1 and CAV-1 in the PTC group compared with the normal tissue group (all $\mathrm{P}<0.01$; Fig. 2B). These data, therefore, suggest that high expression of EHD1 is associated with an increase in the endocytotic recycling of EGFR, possibly contributing to the aggravation of EGFR recycling in PTC.

Correlation of EHD1, EGFR, RAB11FIP3 and CAV-1 in human PTC tissues. A statistical correlation analysis $(\mathrm{n}=72)$, presented in Table III, revealed that the expression of EHD1 was positively correlated with the overexpression of EGFR $(r=0.564 ; \mathrm{P}<0.05), \mathrm{CAV}-1(\mathrm{r}=0.865 ; \mathrm{P}<0.01)$ and RAB11FIP3 $(\mathrm{r}=0.504 ; \mathrm{P}<0.05)$. It was also identified that expression of EGFR was positively correlated with $\mathrm{CAV}-1(\mathrm{r}=0.595 ; \mathrm{P}<0.05)$. These data suggested that high expression of EHD1 and CAV-1 was positively correlated with EGFR, which increased endocytotic recycling of EGFR in PTC.

Clinical significance of EHDI, EGFR, CAV-1 and RAB11FIP3. Protein expression data were analyzed for associations with the

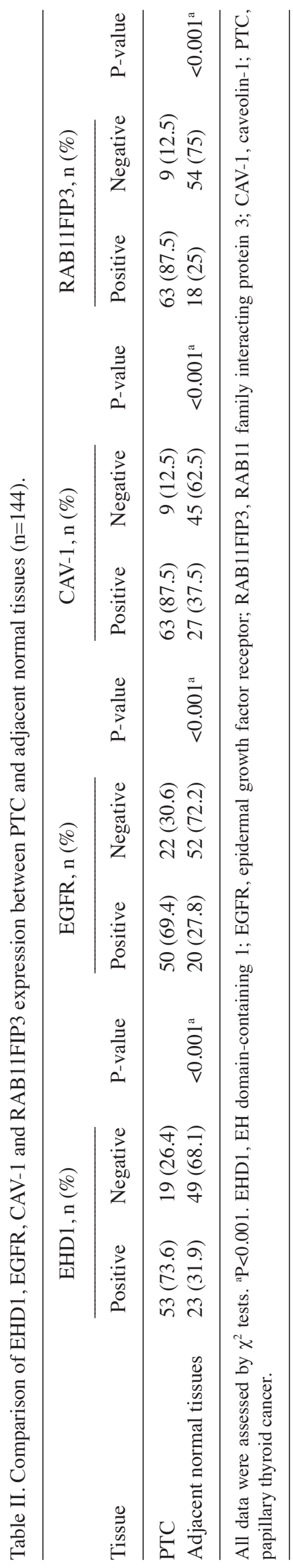


Table III. Correlation between EHD1, EGFR, CAV-1 and RAB 11FIP3 expression in human papillary thyroid carcinoma.

\begin{tabular}{lccc}
\hline Protein & EHD1 & EGFR & CAV-1 \\
\hline $\begin{array}{l}\text { EHD1 } \\
\text { r-value } \\
\text { P-value }\end{array}$ & & & \\
EGFR & & & \\
r-value & & & \\
P-value & 0.564 & & \\
CAV-1 & $0.023^{\mathrm{a}}$ & & \\
r-value & & & \\
P-value & 0.865 & 0.595 & 0.487 \\
RAB11FIP3 & $<0.001^{\mathrm{b}}$ & $0.015^{\mathrm{a}}$ & \\
r-value & & & 0.056 \\
P-value & 0.504 & 0.227 & \\
\hline
\end{tabular}

All data were assessed by Spearman's correlation test; ${ }^{\mathrm{a}} \mathrm{P}<0.05$ and ${ }^{b} \mathrm{P}<0.001$. EHD1, EH domain-containing 1; EGFR, epidermal growth factor receptor; RAB11FIP3, RAB11 family interacting protein 3; CAV-1, caveolin-1.

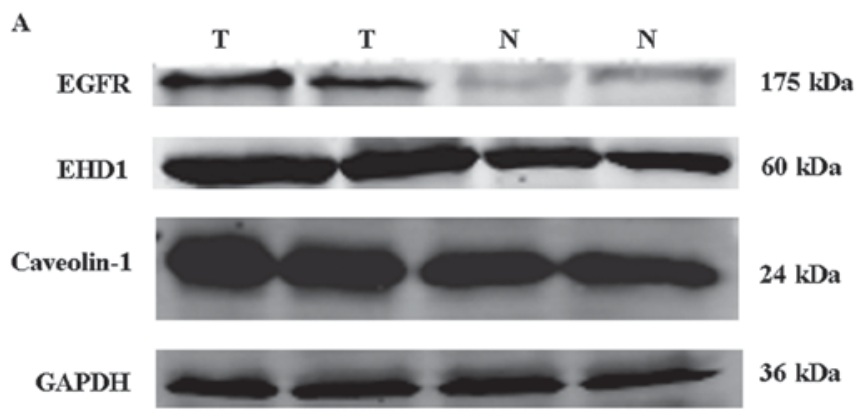

B

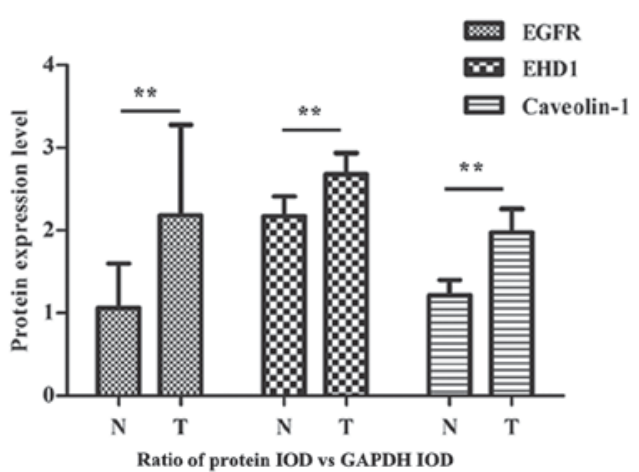

Figure 2. A total of 30 paired tumor and adjacent normal tissues were analyzed for EHD1, EGFR and CAV-1 expression by western blotting. (A) Two representative paired tumor and normal tissues are shown. EHD1, EGFR and CAV-1 expression was normalized to the internal control GAPDH. (B) The mean relative expression in these tumor tissues was significantly higher than that in the paired non-tumorous tissues $(\mathrm{P}<0.01)$. Statistical analysis was performed using a t-test. Fig. 2B was made according to the data of Table V. ${ }^{* *} \mathrm{P}<0.01$. EHD1, EH domain-containing 1; EGFR, epidermal growth factor receptor; CAV-1, caveolin-1; T, tumor; N, normal; IOD, integrated optical density.

clinicopathological features of the patient samples (Table IV). The protein levels of variables were associated with several known clinicopathological characteristics of PTC. The results demonstrated that expression of EHD1 was associated with tumor size $(\mathrm{P}=0.011)$, lymph node metastasis $(\mathrm{P}=0.020)$ and EGFR expression $(\mathrm{P}=0.003)$, but not with any other factors. Expression of $\mathrm{CAV}-1$ was associated with tumor size $(\mathrm{P}=0.013)$ and EGFR expression ( $\mathrm{P}=0.003)$, and EGFR expression was associated with lymph node metastasis $(\mathrm{P}=0.027)$; however, RAB11FIP3 was not associated with any clinicopathological characteristics. In Table V, western blotting results revealed that upregulation of EGFR and CAV-1 was not significantly associated with sex, age, tumor size or lymph node metastasis of the patients. However, overexpression of EHD1 was positively associated with tumor size $(\mathrm{P}=0.044)$.

\section{Discussion}

EGFR was a transporting signaling receptors; however, as a key protein of slow recycling, the function of EHD1 is rarely reported in tumor tissues. However, in one previous study, it was reported to be associated with endocytotic recycling in non-small cell lung cancer (21). Another previous study demonstrated that increased EHD1 and EGFR was able to regulate breast cancer progression, and that the combined expression of EHD1 and EGFR markers may aid physicians in predicting the time to disease recurrence following surgery, and subsequently judge patient prognosis (8). The results of the present study revealed that EHD1 expression is significantly higher in PTC compared with that in tumor-adjacent normal tissues. This is similar to the results of a study by Gao et al (22) in non-small cell lung cancer. The results of IHC and western blotting in the present study indicated that increased EGFR expression was associated with increased expression of EHD1 and that the two were positively associated with PTC. The results of the present study demonstrated that in PTC, increased expression of EHD1 may promote EGFR transport to the cell membrane and then accelerate EGFR for use again, which can promote cell proliferation and malignant transformation. EHD1 alters the EGFR internalization and degradation pathway, which is beneficial to the accumulation of EGFR on the cell surface, ultimately leading to changes in EGFR signaling (23). The present results demonstrated that expression of EHD1 and EGFR was associated with tumor size and lymph node metastasis. Therefore, combined EHD1 and EGFR markers may assist in subsequently judging patient prognosis.

CAV-1, one of the main scaffold proteins in the cell membrane, has a CAV-scaffold binding sequence motif in its intracellular kinase domain, which may connect CAV-1 with EGFR to regulate its activity (24), and this interaction has been demonstrated to serve a function in regulating tumorigenesis (11).

The present study confirmed that the expression of EGFR and CAV-1 in PTC compared with that in tumor-adjacent normal tissues was significantly different and that the expression was associated with lymph node metastasis and tumor size, respectively. These findings are consistent with findings by Lee and Lee (25). Furthermore, elevated expression of CAV-1 in PTC is consistent with the findings of Paskas et al (26). Additionally, studies have identified that overexpression of EGFR is associated with high mortality in undifferentiated 


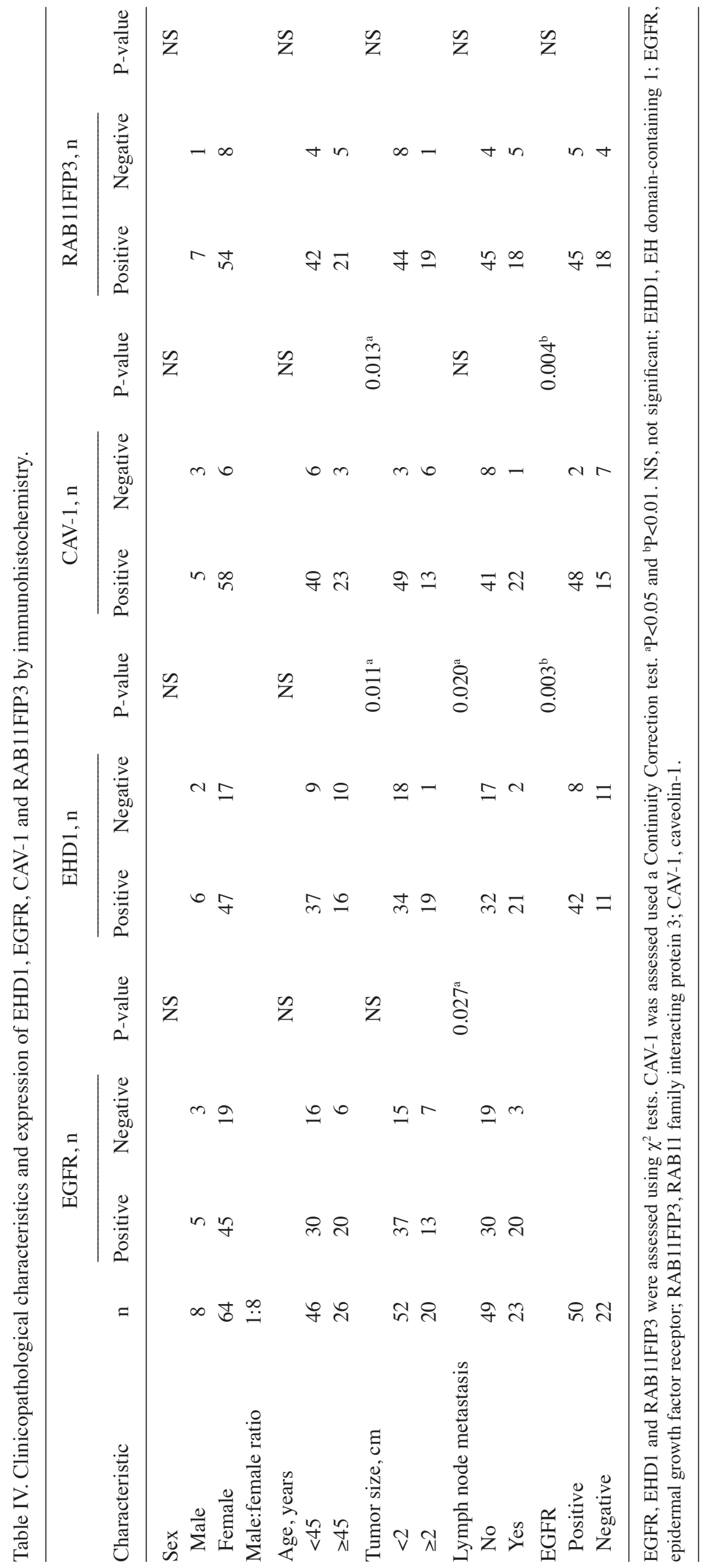


Table V. Clinicopathological characteristics and expression of EHD1, EGFR and CAV-1 by western blotting.

\begin{tabular}{|c|c|c|c|c|c|c|c|}
\hline & & EGFR & & EHD1 & & CAV-1 & \\
\hline Characteristic & $\mathrm{n}$ & Mean score \pm SEM & P-value & Mean score \pm SEM & P-value & Mean score \pm SEM & P-value \\
\hline Sex & & & NS & & NS & & NS \\
\hline Male & 5 & $1.24 \pm 2.07$ & & $2.26 \pm 0.52$ & & $2.70 \pm 1.75$ & \\
\hline Female & 25 & $2.54 \pm 6.79$ & & $2.71 \pm 1.56$ & & $1.91 \pm 1.58$ & \\
\hline Age, years & & & NS & & NS & & NS \\
\hline$<45$ & 16 & $2.45 \pm 7.04$ & & $2.59 \pm 1.59$ & & $1.74 \pm 1.88$ & \\
\hline$\geq 45$ & 14 & $2.16 \pm 5.51$ & & $2.67 \pm 1.32$ & & $2.35 \pm 1.28$ & \\
\hline Tumor size, $\mathrm{cm}$ & & & NS & & $0.044^{\mathrm{a}}$ & & NS \\
\hline$<2$ & 22 & $2.96 \pm 7.08$ & & $2.93 \pm 1.40$ & & $2.32 \pm 1.70$ & \\
\hline$\geq 2$ & 8 & $0.36 \pm 0.34$ & & $1.69 \pm 1.13$ & & $1.24 \pm 0.95$ & \\
\hline Lymph node metastasis & & & NS & & NS & & NS \\
\hline No & 20 & $0.53 \pm 0.45$ & & $2.55 \pm 1.42$ & & $2.31 \pm 1.74$ & \\
\hline Yes & 10 & $0.51 \pm 0.56$ & & $2.8 \pm 1.52$ & & $1.50 \pm 1.19$ & \\
\hline
\end{tabular}

All data were assessed by t-test. ${ }^{\mathrm{a}}<0.05$. EHD1, EH domain-containing 1; EGFR, epidermal growth factor receptor; CAV-1, caveolin-1; NS, not significant; SEM, standard error of the mean.

subtypes of PTC (27,28). It was also identified that CAV-1 expression was positively associated with EGFR expression. The findings in these studies, alongside the present findings, suggest that expression of CAV-1 is able to promote EGFR signaling in PTC.

In normal cells, EHD1 and RAB11 serve functions that regulate recycling from the perinuclear ERC to the plasma membrane (29). Furthermore, RAB11FIP3, a RAB11 effector, is located upstream of EHD1 and participates in endocytotic recycling (30). In the present study, RAB11FIP3 expression was positively correlated with EHD1 expression. Meanwhile, RAB11FIP3 expression was higher in cancer tissues, and this increased expression was statistically significant compared with that in tumor-adjacent normal tissues. We hypothesized that RAB11FIP3 participates in endocytotic recycling and promotes the transport of EGFR in PTC. The Rab11 GTPase effector protein, FIP3, interacts with a part of the dynein motor complex, and this molecular interaction contributes to driving membrane transport at the periphery, and then sorting endosomes to the ERC which are located in a central position (31). Meanwhile, this Rab11 effector, as an interaction ligand of EHDs, coordinates with EHD1 to regulate the exit of receptors from the ERC to the plasma membrane (30). This indicates that high expression of RAB11FIP3 and EHD1 may increase the speed of the endocytotic recycling of EGFR and increase EGFR expression on the cell surface, promoting PTC cell proliferation and malignant transformation.

In conclusion, the high expression of CAV-1 increased the endocytosis of EGFR and EHD1 as the primary proteins involved in recycling. Furthermore, EHD1 may speed up the recycling process by connecting with the Rab11 effector, then promoting the EGFR signal receptor to return to the cell membrane. This is a novel way to increase the expression of EGFR, promoting cell growth and proliferation in PTC. EHD1 is an important factor in promoting tumor progression, and combined with EGFR, it may be more effective than when used alone, at predicting the prognosis of a patient and guiding evaluations of clinical significance.

\section{Acknowledgements}

No applicable.

\section{Funding}

The present study was supported by the National Natural Science Foundation of China (grant nos. 81372611 and 81102081).

\section{Availability of data and materials}

All data generated or analyzed during this study are included in this published article.

\section{Authors' contributions}

YLiu contributed to study design, experimental procedures, performing experiments, analysis and interpretation of data, and drafting of the manuscript. YLia performed experiments, contributed to the data analysis, and drafted parts of the manuscript. ML contributed to experimental procedures and contributed to the data analysis. DL contributed to data collection and data analysis. JT contributed to data analysis and drafted parts of the manuscript. WY contributed to data collection and the interpretation of clinical data. DT made substantial contributions to establishing the histopathological diagnosis, and participated in the interpretation of clinical data, conceptualization, construction and drafting of the manuscript. XJ made substantial contributions to the histopathological diagnosis, conceptualization, construction and drafting of the manuscript. 


\section{Ethics approval and consent to participate}

The use of tissue samples in this study was approved by the Hospital Ethics Committee for Ethical Review of Research Involving Human Subjects at Harbin Medical University (Harbin, China). Patient consent was obtained at the time of the original tissue collection.

\section{Patient consent for publication}

Not applicable.

\section{Competing interests}

The authors declare that they have no competing interests.

\section{References}

1. Siegel RL, Miller KD and Jemal A: Cancer statistics, 2017. CA Cancer J Clin 67: 7-30, 2017.

2. Mohammed AA and El-Shentenawy A: Advanced thyroid cancers: New era of treatment. Med Oncol 31: 49, 2014.

3. Herbst RS: Review of epidermal growth factor receptor biology. Int J Radiat Oncol Biol Phys 59 (Suppl 2): S21-S26, 2004.

4. Hsu F, Nichol A, Toriumi T and De Caluwe A: Miliary metastases are associated with epidermal growth factor receptor mutations in non-small cell lung cancer: A population-based study. Acta Oncol 56: 1175-1180, 2017.

5. Cao WM, Gao Y and Wang XJ: Lack of epidermal growth factor receptor (EGFR)-activating mutations in triple-negative breast cancer in china. Breast Cancer Res 17: 115, 2015.

6. Tanaka Y, Terai Y, Tanabe A, Sasaki H, Sekijima T, Fujiwara S, Yamashita Y, Kanemura M, Ueda M, Sugita M, et al: Prognostic effect of epidermal growth factor receptor gene mutations and the aberrant phosphorylation of Akt and ERK in ovarian cancer. Cancer Boil Ther 11: 50-57, 2011.

7. Mallick UK and American Thyroid A: The revised American Thyroid Association management guidelines 2009 for patients with differentiated thyroid cancer: An evidence-based risk-adapted approach. Clin Oncol (R Coll Radiol) 22: 472-474, 2010.

8. Tong D, Liang YN, Stepanova AA, Liu Y, Li X, Wang L, Zhang F and Vasilyeva NV: Increased Eps15 homology domain 1 and RAB11FIP3 expression regulate breast cancer progression via promoting epithelial growth factor receptor recycling. Tumour Biol 39: 1010428317691010, 2017.

9. Wang S, Wang N, Zheng Y, Zhang J, Zhang F and Wang Z: Caveolin-1: An oxidative stress-related target for cancer prevention. Oxid Med Cell Longev 2017: 7454031, 2017.

10. Nwosu ZC, Ebert MP, Dooley S and Meyer C: Caveolin-1 in the regulation of cell metabolism: A cancer perspective. Mol Cancer 15: 71, 2016.

11. Moreno-Caceres J, Caja L, Mainez J, Mayoral R, Martín-Sanz P, Moreno-Vicente R, Del Pozo MÁ, Dooley S, Egea G and Fabregat I: Caveolin- 1 is required for TGF- $\beta$-induced transactivation of the EGF receptor pathway in hepatocytes through the activation of the metalloprotease TACE/ADAM17. Cell Death Dis 5: e1326, 2014.

12. Xu L, Qu X, Li H, Li C, Liu J, Zheng H and Liu Y: Src/caveolin1-regulated EGFR activation antagonizes TRAIL-induced apoptosis in gastric cancer cells. Oncol Rep 32: 318-324, 2014.

13. Zhang J, Naslavsky N and Caplan S: Rabs and EHDs: Alternate modes for traffic control. Biosci Rep 32: 17-23, 2012.

14. Grant BD and Caplan S: Mechanisms of EHD/RME-1 protein function in endocytic transport. Traffic 9: 2043-2052, 2008.
15. Butterworth MB, Edinger RS, Silvis MR, Gallo LI, Liang X, Apodaca G, Frizzell RA and Johnson JP: Rab1lb regulates the trafficking and recycling of the epithelial sodium channel (ENaC). Am J Physiol Renal Physiol 302: F581-F590, 2012.

16. Bhuin T and Roy JK: Rab11 in disease progression. Int J Mol Cell Med 4: 1-8, 2015

17. Vetter M, Stehle R, Basquin C and Lorentzen E: Structure of Rab11-FIP3-Rabin8 reveals simultaneous binding of FIP3 and Rabin8 effectors to Rab11. Nat Struc Mol Boil 22: 695-702, 2015.

18. Takahashi S, Takei T, Koga H, Takatsu H, Shin HW and Nakayama K: Distinct roles of Rab11 and Arf6 in the regulation of Rab11-FIP3/arfophilin-1 localization in mitotic cells. Genes Cells 16: 938-950, 2011

19. Collins LL, Simon G, Matheson J, Wu C, Miller MC, Otani T, Yu X, Hayashi S, Prekeris R and Gould GW: Rab11-FIP3 is a cell cycle-regulated phosphoprotein. BMC Cell Boil 13: 4, 2012.

20. Iaea DB, Mao S, Lund FW and Maxfield FR: Role of STARD4 in sterol transport between the endocytic recycling compartment and the plasma membrane. Mol Biol Cell 28: 1111-1122, 2017.

21. Chung BM, Tom E, Zutshi N, Bielecki TA, Band V and Band H: Nexus of signaling and endocytosis in oncogenesis driven by non-small cell lung cancer-associated epidermal growth factor receptor mutants. World J Clin Oncol 5: 806-823, 2014.

22. Gao Y, Wang Y, Sun L, Meng Q, Cai L and Dong X: Expression of TGF $\beta-1$ and EHD1 correlated with survival of non-small cell lung cancer. Tumour Biol 35: 9371-9380, 2014

23. Meng Q, Xing Y, Ren T, Lu H, Xi Y, Jiang Z, Hu J, Li C, Sun L, Sun D and Cai L: Mammalian Eps15 homology domain 1 promotes metastasis in non-small cell lung cancer by inducing epithelial-mesenchymal transition. Oncotarget 8: 22433-22442, 2017.

24. Hoop CL, Sivanandam VN, Kodali R, Srnec MN and van der Wel PC: Structural characterization of the caveolin scaffolding domain in association with cholesterol-rich membranes. Biochemistry 51: 90-99, 2012.

25. Lee YM and Lee JB: Prognostic value of epidermal growth factor receptor, $\mathrm{p} 53$ and galectin-3 expression in papillary thyroid carcinoma. J Int Med Res 41: 825-834, 2013.

26. Paskas S, Jankovic J, Marecko I, Išić Denčić T, Tatić S, Cvejić D and Savin S: Caveolin-1 expression in papillary thyroid carcinoma: Correlation with clinicopathological parameters and BRAF mutation status. Otolaryngol Head Neck Surg 150: 201-209, 2014.

27. Chen D, Qi W, Zhang P, Guan H and Wang L: Expression of the estrogen receptor $\alpha$, progesterone receptor and epidermal growth factor receptor in papillary thyroid carcinoma tissues. Oncol Lett 10: 317-320, 2015

28. Tang C, Yang L, Wang N, Li L, Xu M, Chen GG and Liu ZM: High expression of GPER1, EGFR and CXCR1 is associated with lymph node metastasis in papillary thyroid carcinoma. Int J Clin Exp Pathol 7: 3213-3223, 2014.

29. Gidon A, Bardin S, Cinquin B, Boulanger J, Waharte F, Heliot L, de la Salle H, Hanau D, Kervrann C, Goud B and Salamero J: A Rab11A/myosin Vb/Rab11-FIP2 complex frames two late recycling steps of langerin from the ERC to the plasma membrane. Traffic 13: 815-833, 2012.

30. Naslavsky N, Rahajeng J, Sharma M, Jovic M and Caplan S: Interactions between EHD proteins and Rab11-FIP2: A role for EHD3 in early endosomal transport. Mol Boil Cell 17: 163-177, 2006.

31. Horgan CP, Oleksy A, Zhdanov AV, Lall PY, White IJ, Khan AR, Futter CE, McCaffrey JG and McCaffrey MW: Rab11-FIP3 is critical for the structural integrity of the endosomal recycling compartment. Traffic 8: 414-430, 2007.

This work is licensed under a Creative Commons Attribution 4.0 International (CC BY 4.0) License. 